\title{
A INSTABILIDADE DA NOÇÃO DE PALAVRA E A SEGMENTAÇÃO NÃO CONVENCIONAL NA ALFABETIZAÇÃO
}

\author{
THE INSTABILITY OF THE NOTION OF WORD AND THE NON-CONVENTIONAL \\ SEGMENTATION IN LITERACY
}

\begin{abstract}
Carmen Regina Gonçalves Ferreira ${ }^{1}$ Universidade Federal do Rio Grande carmenreginaferreira@yahoo.com.br
\end{abstract}

\section{RESUMO}

No presente artigo, dados de segmentação vocabular, produzidos por uma criança em fase de alfabetização, são descritos e analisados com vistas à discussão concernente a aspectos relevantes para a constituição da noção de palavra. Os dados analisados foram retirados de tarefas de leitura e escrita, a partir das quais foram realizadas entrevistas clínicas, que tinham como foco indagar acerca da noção de palavra (CARRAHER, 1989). Os resultados da análise mostraram que a criança rejeita estruturas constituídas por um ou dois caracteres mesmo quando segmenta todas as palavras de forma convencional, pois não está necessariamente, considerando cada estrutura como palavra, e entende a segmentação vocabular como facilitadora da leitura.

Palavras-chave: Aquisição da escrita. Noção de palavra. Segmentações não convencionais

\begin{abstract}
In the present article, vocabulary segmentation data, produced by a child in the literacy phase, are described and analyzed with a view to the discussion concerning relevant aspects for the constitution of the notion of word. The analyzed data were taken from reading and writing tasks, from which clinical interviews were conducted, which focused on inquiring about the notion of word (CARRAHER, 1989). The results of the analysis showed that the child rejects structures made up of one or two characters even when he segments all words in a conventional way, as he is not necessarily considering each structure as a word, and understands vocabulary segmentation as a facilitator of reading.
\end{abstract}

Key words: Writing acquisition. Word concept. Non-conventional segmentations

1 Pós-doutoranda em Educação (FURG), Doutora em Educação (UFPel) e membro do Grupo de Estudo e Pesquisa em Alfabetização e Letramento (GEALI-FURG). 


\section{Introdução}

Durante o processo de alfabetização é natural encontrar, na produção textual das crianças, enunciados, e até mesmo textos completamente ou parcialmente segmentados, sem espaço gráfico entre as palavras ou com excesso de espaço entre elas, que não condizem com as formas que, convencionalmente, são consideradas corretas no sistema de representação da escrita, resultando, assim, nos casos de segmentação não convencional (FERREIRO; PONTECORVO, 1996).

Esse movimento de escrita que ora une, ora segmenta em lugares não prescritos pela norma, é classificado de três formas distintas de acordo com diferentes motivações: hipossegmentação, caracterizado pela ausência do espaço entre fronteiras vocabulares, segundo as normas ortográficas ('acasadela'/a casa dela); num movimento inverso, têm-se os processos de hipersegmentação, que se referem aos casos em que há alocação de espaço no interior da palavra, não previsto na norma escrita ('amanhe seu'/ amanheceu) (SILVA, 1991) e os casos de híbridos², que misturam as duas ocorrências acima descritas numa mesma sequência vocabular ('foipa sia'/foi passear) (CUNHA, 2010).

Considera-se que esses erros de segmentação durante a alfabetização é um processo natural de quem está tentando entender como o sistema de escrita funciona. E evidencia um período de experimentação com a escrita que sinaliza a instabilidade de compreender o que constitui, por exemplo, o que seja uma palavra gráfica.

Essa instabilidade da noção de palavra com base na segmentação não convencional é a temática a ser abordada no presente artigo, com o objetivo de descrever e analisar dados de segmentação produzidos por uma criança em fase de alfabetização, a fim de discutir aspectos relevantes à constituição da noção de palavra. Especificamente, pretende-se verificar como a criança vai, ao longo da alfabetização, elaborando suas hipóteses de escrita no que diz respeito aos limites gráficos entre as palavras, e como vai evoluindo até chegar, não só à demarcação de fronteiras vocabulares conforme a norma, mas também ao entendimento do que constitui uma palavra no sistema de escrita, a fim de que se possa refletir sobre a importância desse tipo de dado para as práticas pedagógicas.

\section{Pressupostos teóricos}

Segundo os estudos de Ferreiro e Teberosky (1986) a criança, ao entrar para a escola, elabora uma série de hipóteses a respeito do modo como funciona o sistema de escrita de sua língua, pois o ambiente extraescolar está impregnado de informações escritas com as quais ela está constantemente se relacionando. É no ambiente escolar, no entanto, que ela irá testar de forma mais sistemática as suas hipóteses sobre o sistema que está sendo adquirido. É natural, por isso, que na produção escrita inicial sejam encontrados muitos erros relacionados à segmentação da escrita.

No entanto, esses erros devem ser vistos, a partir de uma perceptiva piagetiana, como parte integrante e imprescindível ao processo de aprendizagem e, sobretudo, como uma fonte de dados reveladores das concepções infantis a respeito da constituição de seu sistema linguístico, tanto para pesquisadores sobre os processos de aquisição da escrita, quanto para alfabetizadores, sobre o modo como o alfabetizando está adquirindo o sistema de escrita que requer que ele entenda o que e como a escrita registra (ou nota) (MORAES, 2005).

2 Também nomeados como mesclas (CHACON, 2005) 
Assim, para entender o princípio alfabético, a criança terá que aprender qual o valor sonoro de cada grafema, com quais letras pode ser representado e que posições podem ocupar nas palavras, que precisam ser separadas por espaços em branco na escrita. Convém ressaltar que a apropriação da língua escrita diz respeito não apenas a fonologia da língua, mas também a seus outros aspectos linguísticos (morfológicos, lexicais, sintáticos, semânticos), enunciativos, pragmáticos e discursivos. Esses conhecimentos não são adquiridos naturalmente; ao contrário, constituem uma série de conceitos que precisam ser (re)elaborados durante a aquisição da escrita. Isso significa dizer que a criança precisa reelaborar, em sua mente, uma série de aspectos que a humanidade consagrou na escrita, ao criar esse tipo de notação. "Essas (re)elaborações dizem respeito a conhecimentos que, para adultos alfabetizados, parecem dizer respeito a informações 'já dadas'; ao passo que a criança terá que vivenciar todo um processo cognitivo" (MORAES, 2005, p. 21).

As dificuldades observadas no processo de aprendizagem da escrita no que se refere à noção de palavra, a partir dos processos de segmentação, têm sido o foco de atenção de muitos pesquisadores que se atêm ao estudo da escrita inicial infantil (ABAURRE 1991; BAEZ, 1999; ABAURRE; CAGLIARI, 1985; CHACON, 2004, 2005; CAPRISTANO, 2007; TENANI, 2004, e CUNHA, 2004, 2010). A tarefa de descobrir o que vem a ser uma palavra é, segundo esses autores, um dos muitos problemas que o alfabetizando enfrenta ao se deparar com o sistema de escrita. Tais problemas podem ser de ordem prosódica, morfológica, sintática e semântica. E os critérios utilizados pelas crianças na tentativa de representar o sistema de escrita "configuram-se em indícios da forma como estão construindo um conhecimento sobre a sua língua" (ABAURRE; CAGLIARI, 1985, p. 4). Todos esses estudos descreveram e analisaram a escrita inicial infantil como produto final de uma construção do escrito e colocaram a discussão sobre a noção de palavra no centro dessa problemática.

Abaurre (1991), em relação aos aspectos sintáticos, salienta que os textos espontâneos permitem a observação de situações em que a criança hipossegmenta clíticos com palavras de conteúdo mesmo quando não representam um diálogo, como: 'efalou' (e falou), 'ofim' (o fim), 'naalmadilia' (na armadilha). Diversas vezes esses clíticos não são representados na escrita infantil como uma unidade linguística independente; as crianças os interpretam como se fossem parte integrante da palavra de conteúdo que os sucede. É difícil para a criança em fase de alfabetização entender que letras isoladas também constituem palavras; por isso, os clíticos são vistos pelo aprendiz como não-palavras. Para Ferreiro e Pontecorvo (1996), a criança provavelmente perceberá que palavras são mais do que substantivos, adjetivos ou verbos quando estiver em contato com a língua de forma sistematizada na escola.

De acordo com Abaurre (1991), as crianças parecem, em alguns momentos, quando segmentam seus textos, basear-se também no que estão momentaneamente adotando como forma "canônica" de palavra. No português do Brasil, o acento mais frequente é o das paroxítonas e, interessantemente, as escolhas de onde segmentar as palavras na escrita das crianças coincidem com esse padrão paroxítono. Cagliari (2002) também sugere que boa parte das motivações que resultam em processos de hipersegmentação possa estar sendo influenciada pela acentuação tônica da palavra.

Além de critérios prosódicos, de acordo com Abaurre (1991), critérios semânticos também podem interferir no momento da segmentação de uma palavra, como no exemplo de 'catapulta', grafada como 'cata puta', dois vocábulos existentes na língua de forma independente. Ao analisar esse exemplo, a autora acredita que a criança tenha sido motivada por dois fatores simultaneamente: o reconhecimento de duas palavras do léxico e a preferência natural por paroxítonas dissílabas. Não há como determinar com certeza quais critérios estariam por trás das escolhas de segmentação de cada criança. 
É possível, porém, de acordo com os estudos de Abaurre (1991), verificar que, frequentemente, os aprendizes propõem soluções que parecem estar baseadas em algum tipo de informação relativa às formas canônicas de palavras da língua, percepção que eles já possuem a respeito da organização rítmica e prosódica dos enunciados.

Baez (1999), no seu estudo referente à segmentação não convencional com crianças argentinas, verificou que as justificativas utilizadas pelas crianças a respeito de suas escolhas de onde segmentar partem de critérios de ordem formal, gráfica e quantitativa, concentrando-se mais nos aspectos sintáticos e semânticos. O critério que parece ter maior consenso é o da legibilidade, pois as crianças desde muito cedo percebem a segmentação como algo necessário para garantir o ordenamento e a significação do texto.

A vinculação que as crianças fazem das segmentações com a atividade de leitura confere um sentido mais ligado à necessidade que à simples convenção, o que parece assinalar que as segmentações não constituem em si função linguística, mas são indispensáveis nos momentos de leitura e escrita. No entanto, no caso, a legibilidade remete a uma representação mental de caráter lexical e morfossintático, dada a experiência mais prolongada de interação com os textos (BAEZ, 1999).

A fim de ampliar os estudos que tratam dessa instabilidade da criança, faz-se necessário investigar a segmentação não convencional a partir da construção da palavra, não apenas através do produto final das produções de escrita da criança, mas, também, em contextos de escrita controlada, levando em consideração as próprias explicações infantis produzidas durante seus registros. Desta forma, o presente estudo pode subsidiar reflexões acerca de como o próprio processo de aquisição da escrita vai aos poucos se constituindo sob a ótica de quem o está adquirindo.

\section{Procedimentos metodológicos}

Os dados analisados neste artigo foram extraídos de uma pesquisa mais ampla que teve como objetivo verificar o que provisoriamente crianças pertencentes ao $1^{\circ}, 2^{\circ}$ e $3^{\circ}$ da alfabetização, estavam concebendo como palavra, tendo em vista os possíveis obstáculos de ordem linguística: fonológica, semântica e/ou morfológica bem como lexical. Para o presente estudo serão apresentados apenas os dados de Letícia ${ }^{3}$ (aluna de 7 anos do $2^{\circ}$ ano do ciclo de alfabetização), coletados por meio de três entrevistas ao longo do ano letivo (nos meses de maio, setembro e novembro de 2018). As entrevistas foram conduzidas por meio da utilização do método clínico-crítico piagetiano, conforme proposto por Carraher (1989, p. 31), com o propósito de compreender as razões das escolhas gráficas observadas.

As entrevistadas ocorreram de forma individual e foram conduzidas pela pesquisadora na instituição de ensino, em uma escola pública municipal. Foram utilizadas duas câmeras filmadoras (Canon Vixia HF R800EX e Sony Hdr-Cx 440 Full HD) postadas em diferentes ângulos que mostravam, primeiramente, de forma mais ampla, a criança no momento em que escrevia ou justificava suas escolhas de onde segmentar as palavras, captando suas expressões e seus movimentos. E, em outro ângulo, com close no lápis e na folha de papel, para que se pudesse observar online os comentários verbais da criança bem como registrar o tempo de reparos, pausas, rasuras, a fim de melhor observar hesitações e resoluções de problemas que pudessem surgir.

Os dados apresentados são referentes a uma tarefa que teve como objetivo verificar quais os critérios utilizados pela criança para identificar uma palavra num fluxo contínuo, como podem ser observadas no quadro a seguir:

3 O nome é fictício para preservar a identidade da criança investigada. 


\section{Descrição e análise dos dados de segmentação de palavras em escrita contínua}

$\mathrm{Na} 1^{a}$ tarefa, em que precisava julgar se uma frase toda hipossegmentada poderia ser lida, a criança apresentou dificuldades para ler. No momento em que precisou separar a frase em barras, na $2^{a}$ etapa, realizou da seguinte forma (Fig.01):

\section{UMDIAÝp ÁCAÇAPOUTRqDOCAÇAPOR}

Figura 01 - Segmentação em barras em escrita contínua

As ocorrências de hipossegmentações apresentadas em 'umdia' (um dia) e 'ooutro' (o outro) constituem-se de junturas de um clítico à uma palavra de conteúdo ${ }^{6}$. Diversas vezes esses clíticos não são representados na escrita infantil como uma unidade linguística independente; as crianças os interpretam como se fossem parte integrante da palavra de conteúdo que os sucede (ABAURRE, 1991). É difícil para a criança em fase de alfabetização entender que letras isoladas também constituem palavras, por isso os clíticos são vistos pelo aprendiz como uma não-palavra. Para Ferreiro e Pontecorvo (1996), a criança provavelmente perceberá que palavras são mais do que substantivos, adjetivos ou verbos quando estiver em contato com a língua de forma sistematizada na escola.

De acordo com Abaurre (1991), critérios semânticos também podem interferir no momento da segmentação de uma palavra, como na ocorrência de hipossegmentação 'caça dor' (caçador), que são duas palavras existentes na língua de forma independente. Ao analisar esse exemplo, acredita-se que a criança tenha sido motivada por dois fatores simultaneamente: o reconhecimento de duas palavras do léxico e a preferência natural por paroxítonas dissílabas (ABAURRE,1991).

$\mathrm{Na}$ segunda frase, da $3^{\mathrm{a}}$ tarefa, que precisava ler uma frase toda hipossegmentada, a criança leu com certa dificuldade e na tarefa seguinte realizou a seguinte separação dentro dos quadradinhos:

\section{Aspa redes temou vido}

Nota-se que Letícia acabou criando uma frase de ocorrência de segmentação híbrida. Segundo Cunha (2010), os híbridos, por serem estruturas que apresentam dois processos concomitantes, pressupõem mais de uma movimentação. Com base na análise das filmagens que capturaram o momento exato dessa escrita de Letícia, foi possível perceber que essa segmentação híbrida parece ter sido fruto de um contorno entonacional gerado pela forma como a criança murmurou as palavras enquanto escrevia, originando, nesse caso, a construção de quatro estruturas segmentadas que correspondem a pés binários troqueus, os pés prototípicos das palavras do léxico do português. É, portanto, a forma dessa 'voz baixa' que parece orientar o contorno entonacional em determinados contextos de escrita que influencia as escolhas de onde segmentar.

5 Os clíticos abordados nesse estudo dizem respeito aos monossílabos átonos, como artigos: a(s), o(s); determinadas preposições: com, de, em, por e as contrações com artigos: de $+o(s)=d o(s)$, de $+a(s)=d a(s)$; pronomes pessoais do caso oblíquo: me, te, se, Ihe(s), nos, vos, o(s) e a(s) e algumas conjunções: e, ou, mas.

6 São geralmente substantivos, verbos, adjetivos e advérbios. 
Embora a aquisição da fala não ocorra da mesma forma que a aquisição da escrita, visto que são dois processos distintos de aquisição, há pistas de que, em alguns momentos do percurso de aquisição da escrita esses dois processos podem se entrecruzar, em episódios intitulados por Abaurre (1991) como "vazamentos" de fala na escrita. A partir desta perspectiva, os dados iniciais de escrita podem revelar indícios da representação fonológica dos sistemas linguísticos. Assim, a criança pode acabar se utilizando de conhecimentos fonológicos que tem acerca da língua materna no momento de sua escrita, já que utiliza uma comparação entre as duas realidades (ABAURRE, 1991).

Mesmo depois, diante da pergunta da pesquisadora, se cada uma daquelas estruturas separadas nos quadrinhos eram palavras, a criança assegurou que eram palavras. No entanto, quando a pesquisadora passou para a tarefa seguinte, que consistia em apresentar a mesma oração com e sem segmentação das palavras, a criança percebeu que a segunda forma, com segmentação vocabular de forma convencional, era a mais apropriada para a leitura. Diante disso, solicitou voltar à sua escrita da tarefa anterior e refazer a separação de palavras nos quadradinhos, separando-as de forma convencional.

Verificou-se que a comparação foi importante para a criança refletir e reestruturar a sua escrita frente ao modelo que julgou mais apropriado para a leitura. É possível conferir no trecho a seguir o momento em que se depara com as duas formas de escrita:

Letícia: Essa tá toda junta e essa tá organizada.

Pesquisadora: Essa está organizada?

Letícia: Hunrum. Eu acho que eu fiz alguma coisa de besteira. (ri)

Pesquisadora: Fica melhor ler assim ou assim? (aponta para a frase escrita hipossegmentada e frase segmentada convencionalmente)

Letícia: (aponta para a frase segmentada convencionalmente)

Pesquisadora: Assim? O que diz aqui, então?

Letícia: Aqui?

Pesquisadora: Hum?

Letícia: AS PA RE DES (lê a frase segmentada convencionalmente da tarefa 5)

Pesquisadora: Hum?

Letícia: TEM OU VIDO.

Pesquisadora: Muito Bem. E o que tu fizeste aí?

Letícia: Ó, eu botei sem querer o 'o' e o 'u' juntos.

Pesquisadora: $O$ 'o' e o 'u' tu botou com este aqui.

Letícia: Hunrum, e o 'p' e o 'a' juntos aqui. (referindo-se à estrutura: ASPA REDES TEMOU VI DO) Pesquisadora: 'As paredes' ficaram junto?

Letícia: Hunrum, então eu vou ter que apagar só alguns, mas o do 'a' não o 'as' não.

Letícia: (escreve a frase novamente) Deu, agora fiz certo, ó. Olha só a diferença dessa, tudo junto e essa não tá junto, viu? (compara as frases da folha mostrada pela pesquisadora)

Pesquisadora: Tem diferença, então? O que tem de diferença no que tu fez aqui, então? (pede que Letícia compare suas duas produções da frase)

Letícia: Ó, eu fiz algumas coisas iguaizinhas, olha/

Pesquisadora: Mostra aqui pra nós. Como é que ficou agora?

Letícia: AS PA RE DES/

Pesquisadora: Hum?

Letícia: TÊM

Pesquisadora: Hum?

Letícia: O U VI DO 
Como se observou nessa primeira coleta referente às tarefas de identificação de palavras em escrita contínua, a criança apresentou, primeiramente, casos de segmentação não convencional, mas a última tarefa que apresentava a mesma frase com escrita segmentada convencionalmente e em desacordo com a norma, fez com que a criança refletisse sobre a sua própria escrita realizada na etapa anterior. Tanto que pediu para refazê-la. E diante das duas formas distintas a criança julgou a que deveria ser a mais apropriada e optou pela segmentação convencional. No entanto, isso não significa dizer, que Letícia tenha claro que todas as estruturas linguísticas presentes na sentença sejam consideradas palavras, visto que, em uma de suas declarações, disse que colocou a preposição 'da' separada por espaços em branco porque não poderia ficar junto às palavras 'é' e 'caça'.

Na segunda coleta, na qual todas as etapas se repetiram, mudando apenas as frases, o resultado foi similar. Ao se deparar com a sentença: 'Osolnasceparatodos', na $1^{\text {a }}$ etapa, a criança leu sem grandes dificuldades. Tanto que, quando se perguntou se daria para ler quando as palavras estão todas juntas, sua resposta foi: às vezes, sim. É possível que tal declaração esteja baseada no fato de que, na coleta anterior, Letícia não conseguiu ler e dessa vez, com dificuldades, conseguiu, o que pode indiciar que o foco nas atividades em que deveria ler reduziu-se à oralização das estruturas hipossegmentadas, e não no sentido das palavras nas frases. Segundo Baez (1999), o fato de os alfabetizandos grafarem ou tentarem ler palavras aparentemente sem sentido parece não causar estranhamento a eles, pois, quando precisam escrever pseudopalavras, o fazem sem qualquer tipo de questionamento semântico.

A pesquisadora aproveitou a resposta da criança e questionou por que às vezes não se consegue ler quando está escrito de forma contínua, e a criança justificou com a seguinte resposta:

Letícia: OS (tenta reler a frase novamente a frase hipossegmentada) eu não consigo ler muita coisa de letra junta.

Pesquisadora: Não, por quê?

Letícia: Por causa que eu faço de letra solta.

Pesquisadora: Tu escreves de letra solta?

Letícia: Não tem outra que não seja de letra junta?

Observa-se que Letícia parece entender a função da segmentação como um recurso que facilita o processo de leitura, de forma que solicitou à pesquisadora uma outra frase que não estivesse sem segmentação entre as palavras.

$\mathrm{Na} 2^{a}$ tarefa, que consistia em separar as palavras da frase 'Osolnasceparatodos' com auxílio de barras, a criança segmentou de forma convencional e pareceu muito segura das escolhas realizadas. Logo, sem ocorrências de segmentação não convencional. No entanto, quando a pesquisadora perguntou à criança quantas palavras foram separadas ela responde que foram quatro:

Pesquisadora: Como é que ficou então?

Letícia: O SOL NASCE PARA TODOS

Pesquisadora: Quantas palavrinhas têm aí?

Letícia: Sem o 'o' (letra 'o'), por causa que ele não tá com outra., aí ele não é uma palavra.

Pesquisadora: Então porque tu separou ele (letra 'o')?

Letícia: Por causa que isso devia de tá separado por causa OSOL (fala rápido para demonstrar que não pode ficar junto), ficaria errado, né?

Pesquisadora: Ficaria osol? 
Letícia: Osol.

Pesquisadora: Então, esse aqui (letra 'o') não é uma palavrinha?

Letícia: Não, por causa que ele tem que tá sozinho.

Pesquisadora: Por que ele tá sozinho?

Letícia: Não, por causa que ele tem que tá sozinho. Por causa que aí não é assim, né?

Pesquisadora: Ele teria que ser separado mesmo desse aqui (de 'sol') ?

Letícia: Dessa palavra (aponta para a palavra 'sol'), dessa ('nasce'), dessa ('para'), dessa ('todos').

Pesquisadora: Então quantas palavrinhas eu tenho aí mesmo?

Letícia: Quatro.

Com essa declaração de Letícia constatou-se mais uma vez que, embora segmente de forma convencional, continua desconsiderando os clíticos como palavras. Em sua explicação, novamente argumenta que o artigo só estaria junto a outras palavras se fizesse parte de uma sílaba, como não é, precisa ficar separado. Isso significa dizer que a criança embora apresente uma escrita de palavras segmentadas conforme a norma, ainda impera nesse momento a hipótese do número mínimo de caracteres como uma regularidade possível para a formação de uma palavra (FERREIRO, 1991).

$\mathrm{Na} 3^{\text {a }}$ tarefa seguinte, em que precisou ler a estrutura 'Obaratosaicaro', a leitura ocorreu de forma mais demorada, fazendo movimentos de releitura, até o momento em que conseguiu entender o que estava escrito. Observou-se nessa tarefa um esforço em interpretar o que estava sendo lido. Quanto à tarefa seguinte, que consistia em colocar essa mesma frase dentro de quadradinhos, a criança segmentou as palavras de forma convencional. Ela utilizou a mesma justificativa anterior para dizer por que o artigo ocupou o primeiro quadrado, que mesmo não sendo uma palavra, não poderia ficar 'colado' nas demais.

$\mathrm{Na} 5^{\mathrm{a}}$ tarefa em que recebeu a mesma frase com duas formas diferentes de segmentação vocabular, a criança leu com certa dificuldade a frase com palavras contínuas, já a segmentada convencionalmente leu com muita facilidade, considerando ao final esta como a mais adequada para leitura. Quando terminou essa atividade, a criança solicitou à pesquisadora a sua tarefa anterior, de segmentação nos quadradinhos, para mostrar que a forma como segmentou dentro de cada espaço era a mesma da frase que a criança teria eleito como a mais adequada. Em nenhum momento a pesquisadora fez algum tipo de juízo de valor para uma das duas formas como sendo a adequada; mesmo assim, a criança realizou a escolha de forma segura. E com a mesma segurança defendeu mais uma vez a existência de três palavras nessa frase (barato-sai- caro) em função da necessidade de isolamento do artigo 'o'.

$\mathrm{Na} 1^{\text {a }}$ tarefa da última coleta, realizada no final do ano letivo, Letícia, ao receber a frase: 'Umamãolavaaoutra', apresentou dificuldades em ler e entender a sentença:

Letícia: A A MAMÃO, U MAMÃO LAVA A OUTRA, ãhm? Não entendi.

Pesquisadora: Não entendeu?

Letícia: (sinaliza que não com a cabeça)

Pesquisadora: E a de baixo dá para ler?

Letícia: UMA MÃO LAVA A OUTRA, ah, entendi. UMA MÃO LAVA A OUTRA 
É interessante notar que Letícia começa a sinalizar que os espaços em branco entre as palavras facilitam a leitura e o entendimento do que está escrito. De acordo com Baez (1999), no seu estudo referente à segmentação não convencional com crianças argentinas, o critério que parece ter maior consenso é o da legibilidade, pois as crianças desde muito cedo parecem perceber que a segmentação é necessária para garantir o ordenamento e a significação do texto. Segundo a autora, a vinculação que as crianças fazem das segmentações com a atividade de leitura confere um sentido mais ligado à necessidade que à simples convenção, o que parece assinalar que as segmentações não constituem em si função linguística, mas são indispensáveis nos momentos de leitura e escrita. No entanto, no caso, a legibilidade remete a uma representação mental de caráter lexical e morfossintático, dada a experiência mais prolongada de interação com os textos (BAEZ, 1999).

$\mathrm{Na} 2^{a}$ tarefa quando precisou separar a mesma frase (Umamãolavaaoutra), em quadradinhos, mais uma vez, separou de forma convencional. E quando questionada sobre quantas palavras havia separado, a resposta se manteve como nas demais coletas em que desconsiderou os clíticos, nesse caso os artigos 'uma' e 'a'. Um aspecto relevante nas justificativas da criança, nessa $3^{a}$ entrevista, reside no momento em que explica por que o artigo 'a' precisa ficar isolado por espaços em branco entre as palavras que o cercam:

Pesquisadora: E o 'a' (letra 'a') ficou separado?

Letícia: É.

Pesquisadora: Ele é uma palavrinha?

Letícia: Não.

Pesquisadora: E por que ele está separado então?

Letícia: Por causa que ele é uma vogal. Aqui tá mostrando UMA MÃO LAVA A (ênfase no 'a') OUTRA.

Pesquisadora: Hum.

Letícia: É por isso que o a (letra 'a') está sozinho.

Pesquisadora: Mas ele não é uma palavra?

Letícia: (sinaliza que não com a cabeça)

Essa é a primeira vez que Letícia usa a terminologia vogal para referir o artigo, anteriormente chamava de letra ou de pedacinho. Outro resultado a destacar é a mudança do significado do clítico para a criança. Antes era visto como parte de uma 'sílaba flutuante' que precisava ficar isolado porque não fazia parte de nenhuma das palavras da frase em que estava inserido. Já nessa última coleta, e especificamente nessa frase, a criança explicou que esse artigo não é uma palavra, mas é algo que marca gênero e número na palavra que o segue: 'a outra'. Isso significa dizer que Letícia parece atribuir uma função morfológica ao artigo definido 'a'.

$\mathrm{Na} 3^{\mathrm{a}}$ tarefa, em que precisava ler a frase em escrita contínua, 'Quemvêcaranãovêcoração', a criança apresentou certa dificuldade, que pode ser conferida no trecho que segue:

Letícia: QUEM VICARÃO VE CA RANÃO DE CORAÇÃO

Pesquisadora: $O$ que diz aí?

Letícia: QUEM VÊCARANÃO CARANÃO VÊ CORAÇÃO 
A forma como Letícia leu a frase em ambas as tentativas carecem de sentido. Num primeiro momento, isso não despertou preocupação na criança. No entanto, ao se deparar com a $4^{a}$ tarefa, em que a mesma frase precisava ser separada em quadradinhos, a criança releu, antes de iniciar a escrita, e fez separações em barras, à medida que foi realizando a leitura. E em seguida iniciou a escrita das palavras dentro dos quadradinhos, fazendo a seguinte segmentação vocabular (Fig.02):

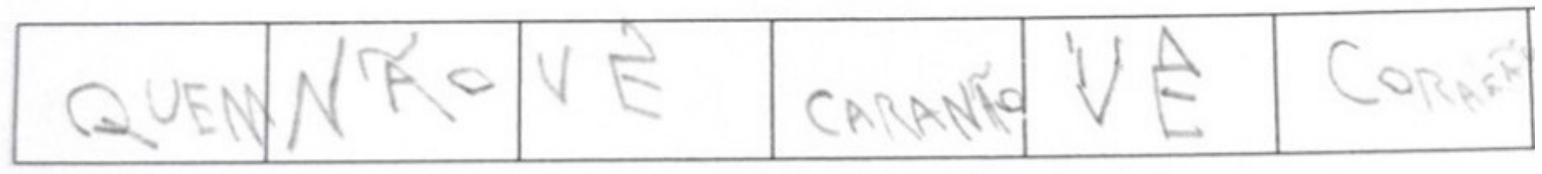

Figura 2 - Segmentação utilizando quadradinhos

Com essa segmentação vocabular pode-se perceber um dado de hipossegmentação, 'caranão' (cara não), que talvez tenha sido motivado pelo contorno entonacional enfatizado pela criança: [quem não vê] [cara não] [vê coração]. Como se pode observar não ficou nenhum quadradinho vazio porque a criança acabou acrescentando o advérbio de negação 'não' à frase. Depois que Letícia permaneceu um certo tempo analisando a forma como distribuiu as palavras, a pesquisadora perguntou se todas as que estavam nos quadrados eram palavras, e a criança responde que não e justifica que a estrutura verbal 'vê' não pode ser considerada como palavra, como se pode observar no fragmento, a seguir:

Pesquisadora: Não? Por que esse aqui (verbo vê) não é uma palavra?

Letícia: Por causa que é a mesma coisa só. Deixa eu te mostrar, se lembra quando eu disse que aqui o (apontando para a primeira sílaba da palavra 'nasce' na frase da coleta anterior O sol nasce para todos), assim ó, aqui, essas duas palavras ('na') só são uma, na verdade essas duas letras ('na'), só fazem uma coisa, na, ne, ni, no, nu.

Pesquisadora: Então por que tu colocasses o vê aí dentro dos quadradinhos? Então, ele é uma palavrinha?

Letícia: Não, o 'vê' não é.

Pesquisadora: E por que ele tá aqui dentro?

Letícia: Por causa que ali tá escrito QUEM VÊ CARANÃO VÊ QUEM NÃO VÊ CARANÃO QUEM NÃO VÊ CARANÃO VÊ CORAÇÃO? Eu acho que eu botei errado.

Pesquisadora: Por que tu acha que está errado?

Letícia: Por causa CARANÃO, isso parece uma palavra estranha. CARA... QUEM NÃO VÊ CARA NÃO VÊ CORAÇÃO.

Observou-se que a criança continuou considerando estruturas de duas letras, por exemplo, a forma flexionada do verbo 'ver', como uma não palavra, ou melhor, como uma sílaba. A ideia já expressa por Letícia, reproduzida no excerto da entrevista recém-apresentada, segundo a qual a contração 'na' ('em' mais 'a') pertenceria à sequência silábica na-ne-ni-no-nu, se confirma em sua resposta relativa à forma 'vê'. No momento em que a criança precisou examinar mais uma vez essa frase se deparou com a estrutura 'caranão' (cara não) que Ihe causou estranhamento. A releitura da frase acabou finalizando de forma convencional: 'Quem vê cara não vê coração'. Em seguida, pediu outra folha para a pesquisadora para refazer sua tarefa anterior e colocar as palavras devidamente distribuídas conforme a última reestruturação. Como se pôde verificar, a criança chegou ao final do ano letivo segmentando as palavras corretamente, mas desconsiderando como palavras estruturas com até três letras. 
Quanto ao julgamento sobre qual a melhor forma da frase escrita, sem e com segmentação vocabular, na $5^{a}$ etapa, a criança acabou novamente lendo sem dificuldades e salientou que na segunda forma escrita as 'partes estavam soltas', referindo-se à frase segmentada de forma convencional, considerando, novamente, essa a melhor forma para ler. Novamente a criança reforça o caráter funcional da segmentação como recurso que facilita, na leitura, o acesso ao significado. Assim, os espaços em branco entre as palavras adquirem o mesmo status da pontuação, já que ambas são recursos linguísticos que orientam o leitor.

\section{Considerações finais}

Os dados analisados no presente artigo parecem reforçar a complexidade do processo de aquisição do sistema de escrita e, embora não possam sugerir generalizações, revelam indícios sobre aspectos do conhecimento linguístico infantil acerca da noção de palavra.

Verificou-se que a criança se utiliza de critérios prosódicos para escrever, originando dados de segmentação não convencional como hipossegmentação, hipersegmentação e ocorrências de híbridos. No entanto, para compreender a leitura, utiliza critérios semânticos como um recurso que facilitaria a compreensão do que se estaria lendo. Atribui, assim, uma funcionalidade à segmentação diretamente ligada ao critério da inteligibilidade, evidenciando a relação assimétrica entre leitura/escrita.

Um dos dados que mais contribuem para ampliar as discussões sobre a problemática da segmentação vocabular durante o processo de alfabetização é o fato de os clíticos continuarem sendo uma não-palavra mesmo que segmentados convencionalmente. Por isso o status do clítico não pode ser analisado apenas pelo aspecto gráfico de segmentação, como um produto final, pois a criança pode segmentá-lo e, ainda assim, não o considerar como palavra. Somente com o apoio das declarações infantis foi possível ter clareza a respeito da relação entre a forma como segmentam e o que realmente consideram como palavra, pois a criança ainda pode estar em conflito com a extensão de letras em uma palavra.

Isso significa dizer que o critério referente ao número mínimo de caracteres, típico do período inicial de aquisição do sistema de escrita, pode perdurar mesmo após a escrita alfabética da criança em fase de alfabetização. Tal concepção desempenha um papel extremamente importante no processo de (re)elaboração da noção de palavra pela criança. Esse aspecto é, portanto, um dos motivos que parece fazer a criança ter certa dificuldade no início da alfabetização, não só para delimitar as fronteiras entre as palavras, mas, também, quando as delimita de forma convencional, entender que estruturas com poucas letras também são palavras.

Desta forma, a segmentação por si só não pode ser o único elemento para interpretar as acepções infantis acerca da palavra porque nem sempre reflete a noção que realmente possuem. O registro gráfico das segmentações realizado pela criança, sem as suas justificativas, revela muito pouco do que elas estão concebendo como palavra. Assim, as justificativas infantis concernentes à palavra podem mostrar tanto convergências quanto divergências com dados de segmentação gráfica de palavras, pois a segmentação convencional não implica necessariamente a reconstrução ou reelaboração da acepção do que constitui uma palavra no sistema de escrita. 
Embora a problemática da segmentação entre as palavras pareça estar resolvida com o tempo, à medida que ocorre a exposição às práticas de leitura e escrita que conferem a esses aprendizes um conhecimento implícito das fronteiras vocabulares, a instabilidade do conceito de palavra, em especial, estruturas com quantidade mínima de caracteres, pode indicar o quanto o ensino de questões ortográficas está descolado das práticas de leitura e escrita. Destaca-se a importância de se propor atividades que possam deixar a criança expressar o que está concebendo sobre os aspectos normativos da língua, que parece ser o ponto central dessa questão, e não restringir o questionamento ao que parece pertinente ao adulto, seja pesquisador ou docente. Nessa perspectiva, entende-se que, tanto o conhecimento das teorias linguísticas quanto o entendimento da trajetória da criança, em busca de compreender como o sistema de escrita funciona, pode proporcionar ao professor alfabetizador melhor acompanhamento das atividades discentes realizadas de forma reflexiva.

Conhecimentos como esses sobre o processo e funcionamento da língua a respeito da delimitação das palavras por espaços em branco permitem ao alfabetizador(a) avaliar as produções iniciais de crianças sem se deter apenas nos aspectos gráficos dessas produções, mas nos aspectos construtivos representativos de um processo cognitivo em vias de evolução. Portanto, saber 'ler' a escrita inicial dos aprendizes requer dos(a) professores(as) alfabetizadores(as) ações pedagógicas alicerçadas em reflexões linguísticas e de uma clara base epistemológica.

\section{Referências}

ABAURRE, Maria Bernadete. M.B.M. \& L.C. CAGLIARI. Textos espontâneos na $1^{a}$ série: evidências da utilização, pela criança, de sua percepção fonética da fala para representar e segmentar a escrita. Em: Cadernos CEDES 14, Recuperando a alegria de ler e escrever. São Paulo: Cortez Editora. (p. 25-29). 1985.

ABAURRE, M. B. M A relevância dos critérios prosódicos e semânticos na elaboração de hipóteses sobre segmentação na escrita inicial. Boletim da ABRALIN, 1991.

BAEZ, Mónica. La problemática de segmentar el texto escrito en palabras: una indagación psicolinguística. In: CÁRDENAS, Viviana I. Segmentación y escritura. Dos estudios sobre adquisición. Ed. Homo Sapiens. Rosario,1999.

CAGLIARI, Luiz Carlos. Alfabetização \& Linguística. São Paulo: Editora Scipione, 2002.

CAPRISTANO, C.C. Mudanças na trajetória da criança em direção à palavra escrita. 2007. 245p. Tese de Doutorado em Linguística Aplicada, Instituto de Estudos da Linguagem, Universidade Estadual de Campinas, Campinas.

CHACON, L. Constituintes prosódicos e letramento em segmentações não-convencionais. Letras de Hoje, Porto Alegre, v. 39, n. 3, 2004, p. 223-232.

CHACON, L. Hipersegmentações na escrita infantil: entrelaçamento de práticas de oralidade e de letramento. Estudos Linguísticos, Campinas, v. 34, 2005, p. 77-86.

CUNHA, A. P. N. A hipo e a hipersegmentação nos dados de aquisição da escrita: um estudo sobre a influência da prosódia. Pelotas, 2004. 132p. Dissertação (Mestrado em Educação) - Universidade Federal de Pelotas.

CUNHA, A. P. N. As segmentações não convencionais na escrita inicial: uma discussão sobre o ritmo linguístico do português brasileiro e europeu. Pelotas, 2010. 190p. Tese (Doutorado em Educação) - Universidade Federal de Pelotas.

FERREIRO, Emília. Com todas as letras. São Paulo: Cortez, 1991.

FERREIRO, Emília. PONTECORVO, Clotilde. Os limites entre as palavras. A segmentação em palavras gráficas. In: FERREIRO, Emília. PONTECORVO, Clotilde. 
MOREIRA, Nadja Ribeiro. HIDALGO, Isabel García. Chapeuzinho Vermelho aprende a escrever. São Paulo: Ática, p.38-66, 1996.

FERREIRO, Emília. TEBEROSKY, Ana. Psicogênese da língua escrita. Porto Alegre: Artes Médicas Sul, 1999.

FERREIRO, Emília. Reflexões sobre a alfabetização. São Paulo: Cortez, 2003.

FERREIRO \& VERNON (1992), La distinción palavra/nombre em niños de 4 e 5 años In: FERREIRO. E. O ingresso na escrita e nas culturas do escrito: seleção de textos de pesquisa. São Paulo Ed.: Cortez, 2013.

SILVA, Ademar da. Alfabetização: a escrita espontânea. São Paulo: Contexto, 1991.

TENANI, L. E. Segmentações não-convencionais e teorias fonológicas. Letras de Hoje, Porto Alegre, v. 39, n. 3 , p. 233-244, 2004.

Recebido em: 15/03/2021

Aceito em: 08/09/2021 